\title{
Geraghty Type Generalized F-Contractions and Related Applications in Partial $b$-Metric Spaces
}

\author{
Deepak Singh, ${ }^{1}$ Varsha Chauhan, ${ }^{2}$ and R. Wangkeeree ${ }^{3}$ \\ ${ }^{1}$ Department of Applied Sciences, NITTTR, Ministry of HRD, Government of India, Bhopal 462002, India \\ ${ }^{2}$ Department of Mathematics, NRI Institute of Research \& Technology, Bhopal, India \\ ${ }^{3}$ Department of Mathematics, Faculty of Science, Naresuan University, Phitsanulok 65000, Thailand \\ Correspondence should be addressed to R. Wangkeeree; rabianw@nu.ac.th
}

Received 31 October 2016; Accepted 6 December 2016; Published 15 March 2017

Academic Editor: Ying Hu

Copyright (C) 2017 Deepak Singh et al. This is an open access article distributed under the Creative Commons Attribution License, which permits unrestricted use, distribution, and reproduction in any medium, provided the original work is properly cited.

\begin{abstract}
The purpose of this paper is to introduce new concepts of $(\alpha, \beta)$-admissible Geraghty type generalized $F$-contraction and to prove that some fixed point results for such mappings are in the perspective of partial $b$-metric space. As an application, we inaugurate new fixed point results for Geraghty type generalized graphic F-contraction defined on partial metric space endowed with a directed graph. On the other hand, one more application to the existence and uniqueness of a solution for the first-order periodic boundary value problem is also provided. Our findings encompass various generalizations of the Banach contraction principle on metric space, partial metric space, and partial $b$-metric space. Moreover, some examples are presented to illustrate the usability of the new theory.
\end{abstract}

\section{Introduction and Preliminaries}

There are a lots of extensions and generalizations of Banach contraction principle [1]. In 1973, Geraghty [2] introduced an interesting contraction and investigated the existence and uniqueness of such mappings in the setting of complete metric spaces by considering an auxiliary function. Later, the $b$-metric concept was launched by Bakhtin [3] as a generalization of a metric to extend the celebrated Banach contraction principle, which was extensively extended by Czerwik [4, 5]. On the other hand, in 1994, Matthews [6] introduced the concept of partial metric spaces wherein the distance of a point from itself may not be zero. Later on, in [7], Karapinar et al. implanted fixed point theorems involving rational expressions in the frame of partial metric space. In 2012, Samet et al. [8] introduced the concept of $\alpha$-contractive and $\alpha$-admissible mappings and established various fixed point results for such type of mappings in the context of complete metric spaces. In 2015, Chandok [9] generalized the concept of $\alpha$-admissible mappings by introducing $(\alpha, \beta)$ admissible mappings.
In recent times, Shukla [10] generalized the concept of both $b$-metric and partial metric space by presenting the partial $b$-metric space. After that, in [11], Mustafa et al. introduced a modified version of partial $b$-metric space. On the other hand, in 2012, Wardowski [12] introduced a new contraction called $F$-contraction and proved a fixed point result as a generalization of the Banach contraction principle. After this, Secelean [13] described a large class of functions by replacing condition $\left(F 2^{\prime}\right)$ instead of condition $(F 2)$ in the definition of $F$-contraction presented by Wardowski [12]. Very recently, Piri and Kumam [14] improved the result of Secelean [13] by replacing condition $\left(F 3^{\prime}\right)$ instead of condition $(F 3)$.

In this work, we introduce the notion of $(\alpha, \beta)$-admissible Geraghty type generalized $F$-contraction and set up some fixed point results concerning such contractions. Moreover, some examples and applications are presented in support of our results. Our proposed definitions and related applications are different as given in [15]. In the sequel, $\mathbb{R}, \mathbb{N}$, and $\mathbb{N}^{*}$ will represent the set of all real numbers, natural numbers, and positive integers, respectively. Some useful definitions 
and auxiliary results, which will be required in the sequel, are recollected here.

Definition 1 (see [4]). Let $X$ be a nonempty set and $s \geq 1$ be a given real number. A function $d: X \times X \rightarrow[0, \infty)$ is called a $b$-metric if for all $x, y, z \in X$ the following conditions are satisfied:

$$
\begin{aligned}
& \left(b_{1}\right) d(x, y)=0 \text { iff } x=y . \\
& \left(b_{2}\right) d(x, y)=d(y, x) . \\
& \left(b_{3}\right) d(x, y) \leq s[d(x, z)+d(z, y)] .
\end{aligned}
$$

The pair $(X, d)$ is called a $b$-metric space. The number $s \geq 1$ is called the coefficient of $(X, d)$.

Definition 2 (see [6]). A partial metric on a nonempty set $X$ is a function $p: X \times X \rightarrow[0, \infty)$ such that for all $x, y, z \in X$

$$
\begin{aligned}
& \text { (p1) } x=y \text { iff } p(x, x)=p(x, y)=p(y, y) \text {; } \\
& \text { (p2) } p(x, x) \leq p(x, y) ; \\
& \text { (p3) } p(x, y)=p(y, x) ; \\
& \text { (p4) } p(x, y) \leq p(x, z)+p(z, y)-p(z, z) .
\end{aligned}
$$

A partial metric space is a pair $(X, p)$ such that $X$ is a nonempty set and $p$ is a partial metric on $X$.

Definition 3 (see [10]). Let $X$ be a nonempty set and $s \geq 1$ be a given real number. A function $p_{b}: X \times X \rightarrow[0, \infty)$ is called a partial $b$-metric if for all $x, y, z \in X$ the following conditions are satisfied:

$$
\begin{aligned}
& \left(p_{b_{1}}\right) x=y \text { iff } p_{b}(x, x)=p_{b}(x, y)=p_{b}(y, y) . \\
& \left(p_{b_{2}}\right) p_{b}(x, x) \leq p_{b}(x, y) . \\
& \left(p_{b_{3}}\right) p_{b}(x, y)=p_{b}(y, x) . \\
& \left(p_{b_{4}}\right) p_{b}(x, y) \leq s\left[p_{b}(x, z)+p_{b}(z, y)\right]-p_{b}(z, z) .
\end{aligned}
$$

The pair $\left(X, p_{b}\right)$ is called a partial $b$-metric space. The number $s \geq 1$ is called the coefficient of $\left(X, p_{b}\right)$.

In the following definition, Mustafa et al. [11] modified Definition 3 in order to find whether each partial $b$-metric $p_{b}$ generates a $b$-metric $d_{p_{b}}$.

Definition 4 (see [11]). Let $X$ be a nonempty set and $s \geq 1$ be a given real number. A function $p_{b}: X \times X \rightarrow[0, \infty)$ is called a partial $b$-metric if for all $x, y, z \in X$ the following conditions are satisfied:

$$
\begin{aligned}
& \left(p_{b_{1}}\right) x=y \text { iff } p_{b}(x, x)=p_{b}(x, y)=p_{b}(y, y) . \\
& \left(p_{b_{2}}\right) p_{b}(x, x) \leq p_{b}(x, y) . \\
& \left(p_{b_{3}}\right) p_{b}(x, y)=p_{b}(y, x) . \\
& \left(p_{b_{4}}\right) p_{b}(x, y) \leq s\left(p_{b}(x, z)+p_{b}(z, y)-p_{b}(z, z)\right)+((1- \\
& s) / 2)\left(p_{b}(x, x)+p_{b}(y, y)\right) .
\end{aligned}
$$

The pair $\left(X, p_{b}\right)$ is called a partial $b$-metric space. The number $s \geq 1$ is called the coefficient of $\left(X, p_{b}\right)$.
Example 5 (see [10]). Let $X=\mathbb{R}^{+}, q>1$ be a constant and $p_{b}: X \times X \rightarrow \mathbb{R}^{+}$be defined by

$$
p_{b}(x, y)=[\max \{x, y\}]^{q}+|x-y|^{q}
$$

for all $x, y \in X$. Then, $\left(X, p_{b}\right)$ is a partial $b$-metric space with the coefficient $s=2^{q-1}>1$, but it is neither a $b$-metric nor a partial metric space.

Remark 6. The class of partial $b$-metric space $\left(X, p_{b}\right)$ is effectively larger than the class of partial metric space, since a partial metric space is a special case of a partial $b$-metric space $\left(X, p_{b}\right)$ when $s=1$. Also, the class of partial $b$-metric space $\left(X, p_{b}\right)$ is effectively larger than the class of $b$-metric space, since a $b$-metric space is a special case of a partial $b$-metric space $\left(X, p_{b}\right)$ when the self-distance $p(x, x)=0$.

Proposition 7 (see [10]). Let $X$ be a nonempty set and let $p$ be a partial metric and d be a $b$-metric with the coefficient $s \geq 1$ on $X$. Then, the function $p_{b}: X \times X \rightarrow[0, \infty)$, defined by $p_{b}(x, y)=p(x, y)+d(x, y)$ for all $x, y \in X$, is a partial bmetric on $X$ with the coefficient $s$.

Proposition 8 (see $[10])$. Let $(X, p)$ be a partial metric space and $q \geq 1$. Then, $\left(X, p_{b}\right)$ is a partial $b$-metric space with the coefficient $s=2^{q-1}$, where $p_{b}$ is defined by $p_{b}(x, y)=$ $[p(x, y)]^{q}$.

Proposition 9 (see [11]). Every partial b-metric $p_{b}$ defines a b-metric $d_{p_{b}}$, where

$$
\begin{array}{r}
d_{p_{b}}(x, y)=2 p_{b}(x, y)-p_{b}(x, x)-p_{b}(y, y), \\
\forall x, y \in X .
\end{array}
$$

Definition 10 (see [11]). A sequence $\left\{x_{n}\right\}$ in a partial $b$-metric space $\left(X, p_{b}\right)$ is said to be

(1) $p_{b}$-convergent to a point $x \in X$ if $p_{b}(x, x)=$ $\lim _{n \rightarrow \infty} p_{b}\left(x, x_{n}\right)$

(2) a $p_{b}$-Cauchy sequence if $\lim _{n, m \rightarrow \infty} p_{b}\left(x_{n}, x_{m}\right)$ exists (and is finite).

A partial $b$-metric space $\left(X, p_{b}\right)$ is said to be $p_{b}$-complete if every $p_{b}$-Cauchy sequence $\left\{x_{n}\right\}$ in $X p_{b}$-converges to a point $x \in X$, such that

$$
p_{b}(x, x)=\lim _{n, m \rightarrow \infty} p_{b}\left(x_{n}, x_{m}\right)=\lim _{n \rightarrow \infty} p_{b}\left(x, x_{n}\right) .
$$

Lemma 11 (see [11]). Let $\left(X, p_{b}\right)$ be a partial b-metric space. Then,

(1) a sequence $\left\{x_{n}\right\}$ is a $p_{b}$-Cauchy sequence in $\left(X, p_{b}\right)$ if and only if it is a b-Cauchy sequence in the b-metric $\operatorname{space}\left(X, d_{p_{b}}\right)$;

(2) $\left(X, p_{b}\right)$ is $p_{b}$-complete if and only if the b-metric space $\left(X, d_{p_{b}}\right)$ is complete. Moreover, $\lim _{n \rightarrow \infty} d_{p_{b}}\left(x_{n}, x\right)=$ 0 if and only if $p_{b}(x, x)=\lim _{n \rightarrow \infty} p_{b}\left(x_{n}, x\right)=$ $\lim _{n, m \rightarrow \infty} p_{b}\left(x_{n}, x_{m}\right)$ 
Definition 12 (see [2]). Let $\Theta$ denote the class of the functions $\theta:[0,+\infty) \rightarrow[0,1)$ which satisfy the condition $\theta\left(t_{n}\right) \rightarrow 1 \Rightarrow$ $t_{n} \rightarrow 0$.

Definition 13 (see [16]). Let $T$ be a self-mapping on $X$ and $\alpha: X \times X \rightarrow[0, \infty)$ be a function. One says that $T$ is an $\alpha$-admissible mapping if

$$
\begin{gathered}
\alpha(x, y) \geq 1 \Longrightarrow \\
\alpha(T x, T y) \geq 1,
\end{gathered}
$$

$$
x, y \in X
$$

Definition 14 (see [9]). Let $X$ be a nonempty set, $T: X \rightarrow$ $X$, and $\alpha, \beta: X \times X \rightarrow[0, \infty)$. One says that $T$ is $(\alpha, \beta)$ admissible if $\alpha(x, y) \geq 1$ and $\beta(x, y) \geq 1$ imply $\alpha(T x, T y) \geq 1$ and $\beta(T x, T y) \geq 1$, for all $x, y \in X$. that

Let $\Phi$ be the set of functions $\phi:[0, \infty) \rightarrow[0, \infty)$ such

(1) $\phi$ is nondecreasing;

(2) $\phi$ is continuous;

(3) $\phi(t)=0 \Leftrightarrow t=0$.

On the other hand, Wardowski [12] introduced the Fcontraction as follows.

Definition 15 . Let $F: \mathbb{R}^{+} \rightarrow \mathbb{R}$ be a mapping satisfying the following:

(F1) $F$ is strictly increasing, that is, for $\alpha, \beta \in \mathbb{R}^{+}$such that $\alpha<\beta$ implies $F(\alpha)<F(\beta)$.

(F2) For each sequence $\left\{\alpha_{n}\right\}$ of positive numbers, $\lim _{n \rightarrow \infty} \alpha_{n}=0$ if and only if $\lim _{n \rightarrow \infty} F\left(\alpha_{n}\right)=-\infty$.

(F3) There exists $k \in(0,1)$ such that $\lim _{\alpha \rightarrow 0^{+}} \alpha^{k} F(\alpha)=0$.

We denote the set of all functions satisfying $(F 1)-(F 3)$ by $F$. In [13], Secelean replaced condition $(F 2)$ by an equivalent but a more simple condition $\left(F 2^{\prime}\right)$.

$\left(F 2^{\prime}\right)$ inf $F=-\infty$,

or also by the following.

$\left(F 2^{\prime \prime}\right)$ There exists a sequence $\left\{\alpha_{n}\right\}_{n=1}^{\infty}$ of positive real numbers such that $\lim _{n \rightarrow \infty} F\left(\alpha_{n}\right)=-\infty$.

Most recently, Piri and Kumam [14] used the following condition $\left(F 3^{\prime}\right)$ instead of $(F 3)$.

$\left(F 3^{\prime}\right) F$ is continuous on $(0, \infty)$.

We denote the set of all functions satisfying $(F 1)$, $\left(F 2^{\prime}\right)$, and $\left(F 3^{\prime}\right)$ by $\Delta_{F}$.

We introduce the following function.

Definition 16. Let $\Delta_{D}$ be the set of all continuous functions $D\left(t_{1}, t_{2}, t_{3}, t_{4}\right): \mathbb{R}^{+4} \rightarrow \mathbb{R}^{+}$satisfying the following: for all $t_{1}, t_{2}, t_{3}, t_{4} \in \mathbb{R}^{+}$, if $t_{i}=t_{j}$ for $i, j=1,2,3,4$, where $i \neq j$, then there exists $\tau>0$ such that $D\left(t_{1}, t_{2}, t_{3}, t_{4}\right)=\tau$.

\section{Main Results}

2.1. Fixed Point Results for $(\alpha, \beta)$-Admissible Geraghty Type Generalized F-Contraction. We start this section by introducing the following definition.

Definition 17. Let $\left(X, p_{b}\right)$ be a partial $b$-metric space and $T: X \rightarrow X$ be a self-mapping. Also, suppose that $\alpha, \beta$ : $X \times X \rightarrow[0, \infty)$, where the pair $(\alpha, \beta)$ is defined as in Definition 14. One says that $T$ is an $(\alpha, \beta)$-admissible Geraghty type generalized $F$-contraction on a partial $b$ metric space $X$, if there exist $F \in \Delta_{F}, D \in \Delta_{D}, \theta \in \Theta$, and $\phi \in \Phi$ such that, for all $x, y \in X$ and $s>1$ with $p_{b}(T x, T y)>0$,

$$
\begin{aligned}
& \alpha(x, y) \beta(x, y) F\left(s^{\epsilon} p_{b}(T x, T y)\right) \leq \theta\left(\phi\left(M_{s}(x, y)\right)\right) \\
& \quad \cdot F\left(N_{s}(x, y)\right) \\
& -D\left(p_{b}(x, y), p_{b}(x, T x), p_{b}(y, T y), p_{b}(T x, T y)\right),
\end{aligned}
$$

where

$$
\begin{aligned}
& M_{s}(x, y)=\max \left\{p_{b}(x, y), p_{b}(x, T x), p_{b}(y, T y),\right. \\
& \left.\frac{p_{b}(x, T y)+p_{b}(y, T x)}{2 s}\right\}, \\
& N_{s}(x, y)=\max \left\{p_{b}(x, y), p_{b}(x, T x), p_{b}(y, T y)\right\}
\end{aligned}
$$

and $\epsilon>1$ is a constant.

Our main result of this paper is the following one.

Theorem 18. Let $\left(X, p_{b}\right)$ be a complete partial b-metric space. Let $T$ be a self-mapping on $X$ satisfying the following conditions:

(1) $T$ is $(\alpha, \beta)$-admissible.

(2) There exists $x_{0} \in X$ such that $\alpha\left(x_{0}, T x_{0}\right) \geq 1$ and $\beta\left(x_{0}, T x_{0}\right) \geq 1$.

(3) $T$ is an $(\alpha, \beta)$-admissible Geraghty type generalized $F$ contraction on $\left(X, p_{b}\right)$.

(4) $T$ is continuous.

Then, $T$ has a unique fixed point $u \in X$; moreover, $p_{b}(u, u)=0$.

Proof. Let $x_{0} \in X$ such that $\alpha\left(x_{0}, T x_{0}\right) \geq 1$ and $\beta\left(x_{0}, T x_{0}\right) \geq$ 1. Define a sequence $\left\{x_{n}\right\}$ in $X$ by $x_{n+1}=T x_{n}$ for all $n \in \mathbb{N}^{*}$. If $x_{n_{0}+1}=x_{n_{0}}$ for any $n_{0} \in \mathbb{N}$, then $x_{n_{0}}$ is a fixed point of $T$. Consequently, assume that $x_{n+1} \neq x_{n}$ for all $n \in \mathbb{N}^{*}$.

Since $T$ is an $(\alpha, \beta)$-admissible mapping, it follows from (2) that $\alpha\left(x_{0}, T x_{0}\right)=\alpha\left(x_{0}, x_{1}\right) \geq 1, \alpha\left(T x_{0}, T x_{1}\right)=\alpha\left(x_{1}\right.$, $\left.x_{2}\right) \geq 1$. By induction, we get

$$
\alpha\left(x_{n}, x_{n+1}\right) \geq 1, \quad \forall n \geq 0 .
$$

Similarly, $\beta\left(x_{n}, x_{n+1}\right) \geq 1$ for all $n \geq 0$. 
By taking $x=x_{n}$ and $y=x_{n+1}$ in (5) and due to (F1), property of $\theta$ and $\phi$, we arrive at

$$
\begin{aligned}
& F\left(p_{b}\left(x_{n}, x_{n+1}\right)\right) \leq F\left(s^{\epsilon} p_{b}\left(T x_{n-1}, T x_{n}\right)\right) \leq \alpha\left(x_{n-1},\right. \\
& \left.\quad x_{n}\right) \beta\left(x_{n-1}, x_{n}\right) F\left(s^{\epsilon} p_{b}\left(T x_{n-1}, T x_{n}\right)\right) \\
& \quad \leq \theta\left(\phi\left(M_{s}\left(x_{n-1}, x_{n}\right)\right)\right) F\left(N_{s}\left(x_{n-1}, x_{n}\right)\right) \\
& \quad-D\left(p_{b}\left(x_{n-1}, x_{n}\right), p_{b}\left(x_{n-1}, x_{n}\right), p_{b}\left(x_{n}, x_{n+1}\right),\right. \\
& \left.\quad p_{b}\left(x_{n}, x_{n+1}\right)\right)
\end{aligned}
$$

where

$$
\begin{aligned}
& M_{s}\left(x_{n-1}, x_{n}\right)=\max \left\{p_{b}\left(x_{n-1}, x_{n}\right), p_{b}\left(x_{n-1}, x_{n}\right),\right. \\
& \left.p_{b}\left(x_{n}, x_{n+1}\right), \frac{p_{b}\left(x_{n-1}, x_{n+1}\right)+p_{b}\left(x_{n}, x_{n}\right)}{2 s}\right\} \\
& \quad=\max \left\{p_{b}\left(x_{n-1}, x_{n}\right), p_{b}\left(x_{n}, x_{n+1}\right)\right\}, \\
& N_{s}\left(x_{n-1}, x_{n}\right)=\max \left\{p_{b}\left(x_{n-1}, x_{n}\right), p_{b}\left(x_{n-1}, x_{n}\right),\right. \\
& \left.p_{b}\left(x_{n}, x_{n+1}\right)\right\}=\max \left\{p_{b}\left(x_{n-1}, x_{n}\right), p_{b}\left(x_{n}, x_{n+1}\right)\right\} .
\end{aligned}
$$

If $\max \left\{p_{b}\left(x_{n-1}, x_{n}\right), p_{b}\left(x_{n}, x_{n+1}\right)\right\}=p_{b}\left(x_{n}, x_{n+1}\right)$, for all $n \in$ $\mathbb{N}^{*}$, from (8) and by the definition of functions $D$ and $\theta$, we deduce that

$$
\begin{aligned}
F & \left(p_{b}\left(x_{n}, x_{n+1}\right)\right) \\
& \leq \theta\left(\phi\left(p_{b}\left(x_{n}, x_{n+1}\right)\right)\right) F\left(p_{b}\left(x_{n}, x_{n+1}\right)\right)-\tau \\
& \leq F\left(p_{b}\left(x_{n}, x_{n+1}\right)\right)-\tau,
\end{aligned}
$$

a contradiction, since $\tau>0$. Thus, it follows that $\max \left\{p_{b}\left(x_{n-1}, x_{n}\right), p_{b}\left(x_{n}, x_{n+1}\right)\right\}=p_{b}\left(x_{n-1}, x_{n}\right)$. Again, from (8) and by the definition of functions $D$ and $\theta$, we have

$$
F\left(p_{b}\left(x_{n}, x_{n+1}\right)\right) \leq F\left(p_{b}\left(x_{n-1}, x_{n}\right)\right)-\tau,
$$

which gives

$$
F\left(p_{b}\left(x_{n}, x_{n+1}\right)\right) \leq F\left(p_{b}\left(x_{n-1}, x_{n}\right)\right) .
$$

Hence, $\left\{p_{b}\left(x_{n}, x_{n+1}\right)\right\}$ is a decreasing sequence of positive real numbers. Repeated use of (11) gives

$$
\begin{gathered}
F\left(p_{b}\left(x_{n}, x_{n+1}\right)\right) \leq F\left(p_{b}\left(x_{n-1}, x_{n}\right)\right)-\tau \\
\leq F\left(p_{b}\left(x_{n-2}, x_{n-1}\right)\right)-2 \tau \\
\vdots \\
F\left(p_{b}\left(x_{n}, x_{n+1}\right)\right) \leq F\left(p_{b}\left(x_{0}, x_{1}\right)\right)-n \tau .
\end{gathered}
$$

Since $F \in \Delta_{F}$, letting the limit as $n \rightarrow \infty$ in (13), we get

$$
\begin{gathered}
\lim _{n \rightarrow \infty} F\left(p_{b}\left(x_{n}, x_{n+1}\right)\right)=-\infty \Longleftrightarrow \\
\lim _{n \rightarrow \infty} p_{b}\left(x_{n}, x_{n+1}\right)=0 .
\end{gathered}
$$

Moreover, from ( $p 2)$, we have the following:

$$
\lim _{n \rightarrow \infty} p_{b}\left(x_{n}, x_{n}\right)=0 .
$$

Now, we will prove that $\left\{x_{n}\right\}$ is a $p_{b}$-Cauchy sequence in $X$. From Lemma 11, we need to prove that $\left\{x_{n}\right\}$ is a $b$-Cauchy sequence in the $b$-metric space $\left(X, d_{p_{b}}\right)$. Suppose on the contrary that there exists $\delta>0$ such that for an integer $k$ there exists integer $n(k)>m(k) \geq k$ such that

$$
d_{p_{b}}\left(x_{m(k)}, x_{n(k)}\right) \geq \delta
$$

For every integer $k$, let $m(k)$ be the least positive integer exceeding $n(k)$ satisfying (16) such that

$$
d_{p_{b}}\left(x_{m(k)}, x_{n(k)-1}\right)<\delta .
$$

Due to triangle inequality and from (16), we get

$$
\begin{aligned}
\delta & \leq d_{p}\left(x_{m(k)}, x_{n(k)}\right) \\
& \leq s d_{p}\left(x_{m(k)}, x_{n(k)-1}\right)+s d_{p}\left(x_{n(k)-1}, x_{m(k)}\right),
\end{aligned}
$$

which on making $k \rightarrow \infty$ and using (17) give rise to

$$
\begin{aligned}
\frac{\delta}{s} & \leq \lim _{k \rightarrow \infty} \inf d_{p_{b}}\left(x_{m(k)}, x_{n(k)-1}\right) \\
& \leq \lim _{k \rightarrow \infty} \sup d_{p_{b}}\left(x_{m(k)}, x_{n(k)-1}\right) \leq \delta .
\end{aligned}
$$

Also, from (17) and (19), we have

$$
\begin{aligned}
\delta \leq & \lim _{k \rightarrow \infty} \sup d_{p_{b}}\left(x_{m(k)}, x_{n(k)}\right) \leq s \delta, \\
d_{p_{b}}\left(x_{m(k)+1}, x_{n(k)}\right) \leq & s d_{p_{b}}\left(x_{m(k)+1}, x_{m(k)}\right) \\
& +s d_{p_{b}}\left(x_{m(k)}, x_{n(k)}\right) \\
\leq & s d_{p_{b}}\left(x_{m(k)+1}, x_{m(k)}\right) \\
& +s^{2} d_{p_{b}}\left(x_{m(k)}, x_{n(k)-1}\right) \\
& +s^{2} d_{p_{b}}\left(x_{n(k)-1}, x_{n(k)}\right) \\
\leq & s d_{p_{b}}\left(x_{m(k)+1}, x_{m(k)}\right)+s^{2} \delta \\
& +s^{2} d_{p_{b}}\left(x_{n(k)-1}, x_{n(k)}\right)
\end{aligned}
$$

which gives

$$
\lim _{k \rightarrow \infty} \sup d_{p_{b}}\left(x_{m(k)+1}, x_{n(k)}\right) \leq s^{2} \delta .
$$

Furthermore,

$$
\begin{aligned}
d_{p_{b}}\left(x_{m(k)+1}, x_{n(k)-1}\right) \leq & s d_{p_{b}}\left(x_{m(k)+1}, x_{m(k)}\right) \\
& +s d_{p_{b}}\left(x_{m(k)}, x_{n(k)-1}\right),
\end{aligned}
$$

which yields

$$
\lim _{k \rightarrow \infty} \sup d_{p_{b}}\left(x_{m(k)+1}, x_{n(k)-1}\right) \leq s \delta .
$$


Utilizing Proposition 9, we have

$$
\begin{aligned}
& \lim _{k \rightarrow \infty} \sup _{p_{b}}\left(x_{m(k)}, x_{n(k)-1}\right) \\
& \quad=2 \lim _{k \rightarrow \infty} \sup p_{b}\left(x_{m(k)}, x_{n(k)-1}\right) .
\end{aligned}
$$

Then, from the above inequality along with (19), we acquire

$$
\begin{aligned}
\frac{\delta}{2 s} & \leq \lim _{k \rightarrow \infty} \inf p_{b}\left(x_{2 m(k)}, x_{2 n(k)-1}\right) \\
& \leq \lim _{k \rightarrow \infty} \sup p_{b}\left(x_{m(k)}, x_{n(k)-1}\right) \leq \frac{\delta}{2} .
\end{aligned}
$$

Analogously, we deduce that

$$
\begin{aligned}
& \lim _{k \rightarrow \infty} \sup p_{b}\left(x_{m(k)}, x_{n(k)}\right) \leq \frac{s \delta}{2}, \\
& \frac{\delta}{2 s} \leq \lim _{k \rightarrow \infty} \sup p_{b}\left(x_{m(k)+1}, x_{n(k)}\right), \\
& \lim _{k \rightarrow \infty} \sup p_{b}\left(x_{m(k)+1}, x_{n(k)-1}\right) \leq \frac{s \delta}{2} .
\end{aligned}
$$

Since $F\left(p_{b}\left(x_{m(k)+1}, x_{n(k)}\right)\right)=F\left(p_{b}\left(T x_{m(k)}, T x_{n(k)-1}\right)\right)>0$, therefore, due to inequality (5), we have

$$
\begin{aligned}
F( & \left.p_{b}\left(x_{m(k)+1}, x_{n(k)}\right)\right) \leq F\left(s^{\epsilon} p_{b}\left(T x_{m(k)}, T x_{n(k)-1}\right)\right) \\
& \leq \alpha\left(x_{m(k)}, x_{n(k)-1}\right) \beta\left(x_{m(k)}, x_{n(k)-1}\right) \\
& \cdot F\left(s^{\epsilon} p_{b}\left(T x_{m(k)}, T x_{n(k)-1}\right)\right) \\
& \leq \theta\left(\phi\left(M_{s}\left(x_{m(k)}, x_{n(k)-1}\right)\right)\right) F\left(N_{s}\left(x_{m(k)}, x_{n(k)-1}\right)\right) \\
& -D\left(p_{b}\left(x_{m(k)}, x_{n(k)-1}\right), p_{b}\left(x_{m(k)}, x_{m(k)+1}\right),\right. \\
& \left.p_{b}\left(x_{n(k)-1}, x_{n(k)}\right), p_{b}\left(x_{m(k)+1}, x_{n(k)}\right)\right) .
\end{aligned}
$$

Utilizing the definition of $M_{s}(x, y)$ and $N_{s}(x, y)$ along with inequalities (25)-(26) gives rise to

$$
\begin{aligned}
& \lim _{k \rightarrow \infty} \sup M_{s}\left(x_{m(k)}, x_{n(k)-1}\right) \leq \frac{\delta}{2}, \\
& \lim _{k \rightarrow \infty} \sup N_{s}\left(x_{m(k)}, x_{n(k)-1}\right) \leq \frac{\delta}{2} .
\end{aligned}
$$

Indeed,

$$
\begin{gathered}
M_{s}\left(x_{m(k)}, x_{n(k)-1}\right)=\max \left\{p_{b}\left(x_{m(k)}, x_{n(k)-1}\right),\right. \\
p_{b}\left(x_{m(k)}, x_{m(k)+1}\right), p_{b}\left(x_{n(k)-1}, x_{n(k)}\right), \\
\left.\frac{p_{b}\left(x_{m(k)}, x_{n(k)}\right)+p_{b}\left(x_{n(k)-1}, x_{m(k)+1}\right)}{2 s}\right\} .
\end{gathered}
$$

so that

$$
\begin{aligned}
& \lim _{k \rightarrow \infty} \sup M_{s}\left(x_{m(k)}, x_{n(k)-1}\right) \\
& \quad \leq \max \left\{\frac{\delta}{2}, 0,0, \frac{1}{2 s}\left[\frac{s \delta}{2}+\frac{s \delta}{2}\right]\right\} \leq \frac{\delta}{2},
\end{aligned}
$$

By repeating the above technique, one can easily arrive at

$$
\lim _{k \rightarrow \infty} \sup N_{s}\left(x_{m(k)}, x_{n(k)-1}\right) \leq \max \left\{\frac{\delta}{2}, 0,0\right\} \leq \frac{\delta}{2} .
$$

From (27) together with (28), we have

$$
\begin{aligned}
& F(\left.s \frac{\delta}{2 s}\right) \leq \lim _{k \rightarrow \infty} \alpha\left(x_{m(k)}, x_{n(k)-1}\right) \beta\left(x_{m(k)}, x_{n(k)-1}\right) \\
& \cdot F\left(s^{\epsilon} \sup p_{b}\left(T x_{m(k)}, T x_{n(k)-1}\right)\right) \\
& \leq \lim _{k \rightarrow \infty} \theta\left(\phi\left(M_{s}\left(x_{m(k)}, x_{n(k)-1}\right)\right)\right) \\
& \cdot F\left(N_{s}\left(x_{m(k)}, x_{n(k)-1}\right)\right)-\tau, \\
& F\left(\frac{\delta}{2}\right) \leq \lim _{k \rightarrow \infty} \theta\left(\phi\left(M_{s}\left(x_{m(k)}, x_{n(k)-1}\right)\right)\right) F\left(\frac{\delta}{2}\right),
\end{aligned}
$$

which implies that

$$
1 \leq \lim _{k \rightarrow \infty} \theta\left(\phi\left(M_{s}\left(x_{m(k)}, x_{n(k)-1}\right)\right)\right)
$$

which yields

$$
\lim _{k \rightarrow \infty} \theta\left(\phi\left(M_{s}\left(x_{m(k)}, x_{n(k)-1}\right)\right)\right)=1 .
$$

Utilizing the definition of $\theta$ and $\phi$, we obtain

$$
\begin{aligned}
& \lim _{k \rightarrow \infty} \phi\left(M_{s}\left(x_{m(k)}, x_{n(k)-1}\right)\right)=0 \Longrightarrow \\
& \lim _{k \rightarrow \infty} M_{s}\left(x_{m(k)}, x_{n(k)-1}\right)=0=\lim _{k \rightarrow \infty} d_{p}\left(x_{m(k)}, x_{n(k)}\right),
\end{aligned}
$$

a contradiction. Thus, we have proved that $\left\{x_{n}\right\}$ is a $b$ Cauchy sequence in the $b$-metric space $\left(X, d_{p_{b}}\right)$; then, from Lemma $11,\left\{x_{n}\right\}$ is a $p_{b}$-Cauchy sequence in the partial $b$-metric space $\left(X, p_{b}\right)$. As $\left(X, p_{b}\right)$ is complete, by Lemma $11, b$-metric space $\left(X, d_{p_{b}}\right)$ is $b$-complete. Therefore, the sequence $\left\{x_{n}\right\}$ converges to some point $u \in X$; that is, $\lim _{n \rightarrow \infty} d_{p_{b}}\left(x_{n}, u\right)=0$. Again, from Lemma 11,

$$
\lim _{n \rightarrow \infty} p_{b}\left(x_{n}, u\right)=\lim _{n, m \rightarrow \infty} p_{b}\left(x_{n}, x_{m}\right)=p(u, u)=0 .
$$

Next, we will show that $u$ is the fixed point of $T$ reasoning by contradiction. Suppose that $p_{b}(u, T u)>0$; inequality (5) implies that

$$
\begin{aligned}
& F\left(p_{b}\left(T u, x_{n+1}\right)\right) \leq F\left(s^{\epsilon} p_{b}\left(T u, T x_{n}\right)\right) \leq \alpha\left(u, x_{n}\right) \\
& \cdot \beta\left(u, x_{n}\right) F\left(s^{\epsilon} p_{b}\left(T u, T x_{n}\right)\right) \leq \theta\left(\phi\left(M_{s}\left(u, x_{n}\right)\right)\right) \\
& \cdot F\left(N_{s}\left(u, x_{n}\right)\right)-D\left(p_{b}\left(u, x_{n}\right), p_{b}(u, T u),\right. \\
& \left.\quad p_{b}\left(x_{n}, x_{n+1}\right), p_{b}\left(T u, x_{n+1}\right)\right),
\end{aligned}
$$


in which

$$
\begin{aligned}
& M_{s}\left(u, x_{n}\right)=\max \left\{p_{b}\left(u, x_{n}\right), p_{b}(u, T u),\right. \\
& \left.p_{b}\left(x_{n}, x_{n+1}\right), \frac{p_{b}\left(u, x_{n+1}\right)+p_{b}\left(x_{n}, T u\right)}{2 s}\right\}, \\
& \lim _{n \rightarrow \infty} M_{s}\left(u, x_{n}\right)=\max \left\{p_{b}(u, u), p_{b}(u, T u), p_{b}(u, u),\right. \\
& \left.\frac{p_{b}(u, u)+p_{b}(u, T u)}{2 s}\right\}=p_{b}(u, T u) .
\end{aligned}
$$

By repeating the same process as mentioned above, we have

$$
\lim _{n \rightarrow \infty} N_{s}\left(u, x_{n}\right)=p_{b}(u, T u)
$$

Making limit $n \rightarrow \infty$ in (37) and due to inequalities (38) and (39), property of $F$ function together with continuity of $T$, this gives rise to

$$
\begin{aligned}
& F\left(p_{b}(T u, u)\right) \\
& \quad \leq \lim _{n \rightarrow \infty} \theta\left(\phi\left(M_{s}\left(u, x_{n}\right)\right)\right) F\left(p_{b}(u, T u)\right)-\tau, \\
& F\left(p_{b}(T u, u)\right) \\
& \quad \leq \lim _{n \rightarrow \infty} \theta\left(\phi\left(M_{s}\left(u, x_{n}\right)\right)\right) F\left(p_{b}(u, T u)\right), \\
& 1 \leq \lim _{n \rightarrow \infty} \theta\left(\phi\left(M_{s}\left(u, x_{n}\right)\right)\right) .
\end{aligned}
$$

Using the definitions of $\theta$ and $\phi$, the above inequality turns into

$$
\begin{array}{r}
\lim _{n \rightarrow \infty} \theta\left(\phi\left(M_{s}\left(u, x_{n}\right)\right)\right)=1, \\
\lim _{n \rightarrow \infty} \phi\left(M_{s}\left(u, x_{n}\right)\right)=0,
\end{array}
$$

which implies

$$
\lim _{n \rightarrow \infty} M_{s}\left(u, x_{n}\right)=0
$$

which is impossible. This contradiction proves that $p_{b}(T u$, $u)=0$; that is, $T u=u$. Hence, we assert that $u$ is a fixed point of $T$.

To prove the uniqueness of the fixed point $u$, let $v$ be another fixed point of $T$; that is, $T v=v$, such that $p_{b}(u, v)>0$. From (5), we obtain that

$$
\begin{aligned}
& F\left(p_{b}(u, v)\right)=F\left(p_{b}(T u, T v)\right) \leq \alpha(u, v) \beta(u, v) \\
& \quad \cdot F\left(s^{\epsilon} p_{b}(T u, T v)\right) \leq \theta\left(\phi\left(M_{s}(u, v)\right)\right) \\
& \quad \cdot F\left(N_{s}(u, v)\right) \\
& \quad-D\left(p_{b}(u, v), p_{b}(u, T u), p_{b}(v, T v), p_{b}(T u, T v)\right),
\end{aligned}
$$

where

$$
\begin{aligned}
& M_{s}(u, v)=\max \left\{p_{b}(u, v), p_{b}(u, T u), p_{b}(v, T v),\right. \\
& \left.\frac{p_{b}(u, T v)+p_{b}(v, T u)}{2 s}\right\}=p_{b}(u, v), \\
& N_{s}(u, v)=\max \left\{p_{b}(u, v), p_{b}(u, T u), p_{b}(v, T v)\right\} \\
& =p_{b}(u, v) .
\end{aligned}
$$

Therefore, using the definition of $\theta$ and $D \in \Delta_{D}$ along with the value of $M_{s}(u, v)$ and $N_{s}(u, v)$, the above inequality turns into the following:

$$
\begin{aligned}
& F\left(p_{b}(u, v)\right) \leq \theta\left(\phi\left(p_{b}(u, v)\right)\right) F\left(p_{b}(u, v)\right)-\tau, \\
& F\left(p_{b}(u, v)\right) \leq F\left(p_{b}(u, v)\right)-\tau,
\end{aligned}
$$

which gives a contradiction. Hence, $p_{b}(T u, T v)=p_{b}(u, v)=$ 0 ; that is, $u=v$. Thus, we conclude that the fixed point of $T$ is unique. Next, we will prove that $p_{b}(u, u)=0$. If $p_{b}(T u, T u)=p_{b}(u, u)>0$, then, from (5) and by applying the routine calculation as mentioned above, we can get

$$
\begin{aligned}
F\left(p_{b}(u, u)\right) & =F\left(p_{b}(T u, T u)\right) \\
& \leq \alpha(u, u) \beta(u, u) F\left(s^{\epsilon} p_{b}(T u, T u)\right) \\
& \leq \theta\left(\phi\left(p_{b}(u, u)\right)\right) F\left(p_{b}(u, u)\right)-\tau \\
& \leq F\left(p_{b}(u, u)\right)-\tau,
\end{aligned}
$$

a contradiction. Thus, $p_{b}(u, u)=0$.

This completes the proof of the theorem.

Now, we present an example which shows the superiority of our assertion.

Example 19. Let $X=[0,20]$ be equipped with the partial order relation $\preceq$ defined by

$$
\begin{aligned}
& x \preceq y \Longleftrightarrow \\
& x>y
\end{aligned}
$$

and the function $p_{b}: X \times X \rightarrow[0, \infty)$ is defined by

$$
p_{b}(x, y)=[\max \{x, y\}]^{2}
$$

for all $x, y \in X$, where $s=2$. It is obvious that $\left(X, p_{b}\right)$ is a complete partial $b$-metric space. Let the mapping $T: X \rightarrow X$ be defined by

$$
T x=\frac{1}{16} x^{3} e^{-x^{3}} .
$$

And we define the mapping $\alpha, \beta: X \times X \rightarrow[0, \infty)$ by

$$
\begin{aligned}
& \alpha(x, y)= \begin{cases}1, & x, y \in[0,1], \\
0, & \text { otherwise, }\end{cases} \\
& \beta(x, y)= \begin{cases}1, & x, y \in[0,1], \\
0, & \text { otherwise. }\end{cases}
\end{aligned}
$$


By the definition of $T$, it is clear that $\alpha(T x, T y) \leq 1$ and $\beta(T x, T y) \leq 1$. Also, there exists $x_{0}=0$ in $X$ such that $\alpha(0, T 0)=\alpha(0,0) \geq 1$ and $\beta(0, T 0)=\beta(0,0) \geq 1$.

Define $\theta:[0, \infty) \rightarrow[0,1)$ by $\theta(t)=1 /(t+1)$. And let $\phi:$ $[0, \infty) \rightarrow[0, \infty)$ be given by $\phi(t)=t / 100$. Let $F(t)=\log t+t$ for all $t \in \mathbb{R}^{+}$.

Without loss of generality, we may take $x, y \in X$ such that $x>y$. In order to check the contractive condition (5) of Theorem 18, we have to consider the following cases.

Case 1. If $x, y \in[0,1]$, then

$$
\begin{aligned}
\text { LHS } & =\alpha(x, y) \beta(x, y) F\left(s^{\epsilon} p_{b}(T x, T y)\right) \\
& =F\left(2^{\epsilon} \max \left\{\frac{1}{16} x^{3} e^{-x^{3}}, \frac{1}{16} y^{3} e^{-y^{3}}\right\}^{2}\right) \\
& \leq F\left(2^{\epsilon} \frac{1}{16} \max \left\{x^{3} e^{-x^{3}}, y^{3} e^{-y^{3}}\right\}^{2}\right) \\
& \leq F\left(2^{\epsilon-4} x^{6} e^{-2 x^{3}}\right) \\
& \leq \log \left(2^{\epsilon-4} x^{6} e^{-2 x^{3}}\right)+2^{\epsilon-4} x^{6} e^{-2 x^{3}} .
\end{aligned}
$$

For RHS, utilizing the definitions of $M_{s}(x, y)$ and $N_{s}(x, y)$, one can easily verify that $M_{s}(x, y)=x^{2}$ and $N_{s}(x, y)=x^{2}$. Hence,

$$
\begin{aligned}
\text { RHS } & =\theta\left(\phi\left(x^{2}\right)\right) F\left(x^{2}\right)-\tau \\
& =\frac{100\left(\log x^{2}+x^{2}\right)}{x^{2}+100}-\tau,
\end{aligned}
$$

for all $x, y \in[0,1]$ and using the above hypotheses that $x>$ 0 . Figures 1 and 2 demonstrate that the RHS expression (with green curve) dominates the LHS expression (with pink curve) for $x, y \in[0,1]$, which validates our inequality.

From Figures 1 and 2, it is easy to find that condition (5) holds for all $x, y \in[0,1]$ with $\epsilon \in(1,2.5]$ and $\tau \in(0,1.5]$.

Case 2. If $x, y \in(1,20]$, then $\alpha(x, y) \beta(x, y)=0$. From (5), we arrive at

$$
\begin{aligned}
\text { LHS } & =\alpha(x, y) \beta(x, y) F\left(s^{\epsilon} p_{b}(T x, T y)\right)=0 \\
& \leq \frac{100\left(\log x^{2}+x^{2}\right)}{x^{2}+100}-\tau .
\end{aligned}
$$

Figures 3 and 4 show that the RHS expression (with green curve) overshadows the LHS expression (with pink curve), which authenticates our inequality.

From Figures 3 and 4, it is clear that condition (5) holds for all $x, y \in(1,20]$.

Case 3. If $y \in[0,1]$ and $x \in(1,20]$, then Case 3 is similar to Case 2, and therefore we skip the details.

Thus, all the conditions of Theorem 18 are fulfilled and $0 \in X$ is a unique fixed point of the involved mapping $T$ (see Figure 5).
Remark 20. If $\beta(x, y)=1$ in Definition 17 , then we say that $T$ is $\alpha$-admissible Geraghty type generalized $F$-contraction on $X$.

The following example highlights the above remark.

Example 21. Let $X=\{0,1,2,3\}$ and mapping $T: X \rightarrow X$ is defined by

$$
\begin{aligned}
& T 0=0, \\
& T 1=2, \\
& T 2=1, \\
& T 3=0 .
\end{aligned}
$$

We define the mappings $\alpha, \beta: X \times X \rightarrow[0, \infty)$ by

$$
\begin{aligned}
& \alpha(x, y)= \begin{cases}1, & x, y \in\{0,3\}, \\
0, & \text { otherwise, }\end{cases} \\
& \beta(x, y)= \begin{cases}1, & x, y \in\{2,3\}, \\
0, & \text { otherwise. }\end{cases}
\end{aligned}
$$

It is easy to observe that $T$ is an $\alpha$-admissible but not a $\beta$ admissible mapping.

Remark 22. If $\alpha(x, y)=1$ in Definition 17, then we say that $T$ is $\beta$-admissible Geraghty type generalized $F$-contraction on $X$.

The following example validates the aforesaid remark.

Example 23. Let $X=\{a, b, c, d\}$ and mapping $T: X \rightarrow X$ is given by

$$
\begin{aligned}
& T a=d, \\
& T b=b, \\
& T c=a, \\
& T d=a .
\end{aligned}
$$

We define the mappings $\alpha, \beta: X \times X \rightarrow[0, \infty)$ by

$$
\begin{aligned}
& \alpha(x, y)= \begin{cases}1, & x, y \in\{c, d\}, \\
0, & \text { otherwise, }\end{cases} \\
& \beta(x, y)= \begin{cases}1, & x, y \in\{a, b, d\}, \\
0, & \text { otherwise. }\end{cases}
\end{aligned}
$$

One can verify that $T$ is a $\beta$-admissible but not an $\alpha$ admissible mapping.

Remark 24. If $\alpha(x, y)=\beta(x, y)=1$ in Definition 17 , then we say that $T$ is Geraghty type generalized $F$-contraction on $X$.

Remark 25. If $M_{s}(x, y)=N_{s}(x, y)=p_{b}(x, y)$ in Definition 17 , then we say that $T$ is $(\alpha, \beta)$-admissible Geraghty type $F$-contraction on $X$. 


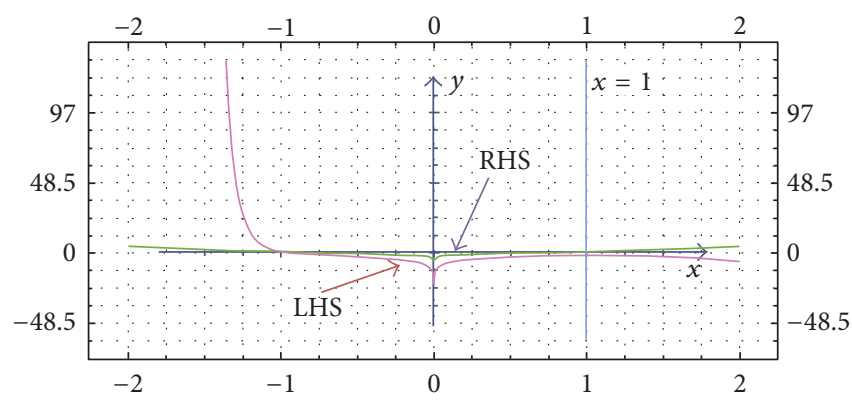

FIGURE 1: Plot of inequality for Case 1 with $\epsilon=1.1$ and $\tau=0.1$.

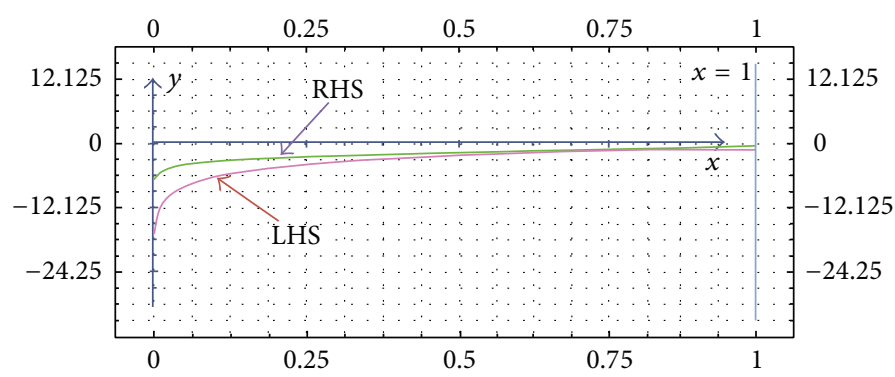

Figure 2: Plot of inequality for Case 1 with $\epsilon=2.5$ and $\tau=1.5$.

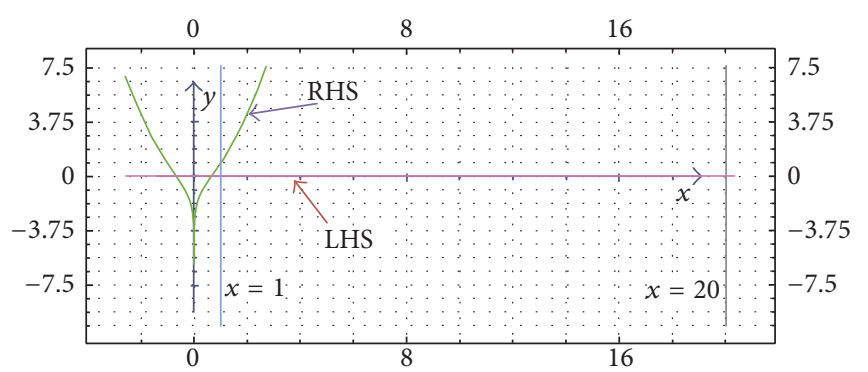

FIgURe 3: Plot of inequality for Case 2 with $\tau=0.1$.

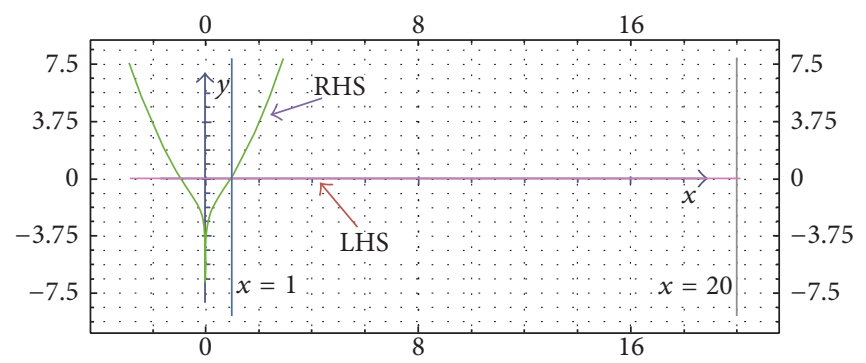

FIGURE 4: Plot of inequality for Case 2 with $\tau=0.8$.

2.2. Fixed Point Results for Geraghty Type Generalized FContraction with a Partial Order

Definition 26 . Let $(X, \preceq)$ be a partially ordered set and $T$ : $X \rightarrow X$ be a given mapping. One says that $T$ is nondecreasing with respect to $\preceq$ if

$$
\begin{gathered}
x \preceq y \Longrightarrow \\
T x \preceq T y,
\end{gathered}
$$

Theorem 27. Let $\left(X, \preceq, p_{b}\right)$ be a complete ordered partial bmetric space. Let $T: X \rightarrow X$ be a nondecreasing mapping with respect to $\preceq$. Suppose that the following conditions hold:

(1) There exists $x_{0} \in X$ such that $x_{0} \preceq T x_{0}$.

(2) $T$ is a Geraghty type generalized F-contraction on $\left(X, p_{b}\right)$.

(3) $T$ is continuous.

Then, $T$ has a unique fixed point $u \in X$; moreover, $p_{b}(u, u)=0$. 


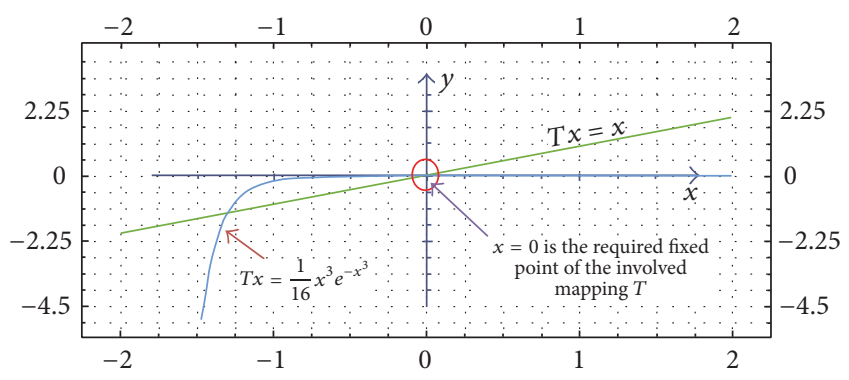

FIGURE 5: Fixed point of the mapping $T$.

Proof. Let $\alpha, \beta: X \times X \rightarrow[0, \infty)$ be defined by

$$
\begin{aligned}
& \alpha(x, y)= \begin{cases}1, & \text { if } x \leq y \text { or } y \leq x, \\
0, & \text { otherwise, }\end{cases} \\
& \beta(x, y)= \begin{cases}1, & \text { if } x \leq y \text { or } y \leq x, \\
0, & \text { otherwise. }\end{cases}
\end{aligned}
$$

Due to condition (1), we have $\alpha\left(x_{0}, T x_{0}\right) \geq 1$ and $\beta\left(x_{0}, T x_{0}\right) \geq$ 1. Using the nondecreasing property of $T$, we arrive at

$$
\begin{aligned}
\alpha(x, y) & \geq 1 \Longrightarrow \\
x & \leq y \\
\text { or } y & \leq x \Longrightarrow \\
T x & \leq T y \\
\text { or } T y & \leq T x \Longrightarrow \\
\alpha(T x, T y) & \geq 1 .
\end{aligned}
$$

Similarly, we obtain that $\beta(x, y) \geq 1 \Rightarrow \beta(T x, T y) \geq 1$.

Thus, $T$ is $(\alpha, \beta)$-admissible. Hence, it is easy to conclude that $T$ is $(\alpha, \beta)$-admissible Geraghty type generalized $F$ contraction. It follows from Theorem 18 that $T$ has a unique fixed point if it is continuous.

\section{Some Consequences}

From Theorem 18, if $s=1$, we deduce the following theorem.

Theorem 28. Let $(X, p)$ be a complete partial metric space. Let $T$ be a self-mapping on $X$ satisfying the following conditions:

(1) $T$ is $(\alpha, \beta)$-admissible.

(2) There exists $x_{0} \in X$ such that $\alpha\left(x_{0}, T x_{0}\right) \geq 1$ and $\beta\left(x_{0}, T x_{0}\right) \geq 1$.

(3) There exist $F \in \Delta_{F}, D \in \Delta_{D}, \theta \in \Theta$, and $\phi \in \Phi$ such that, for all $x, y \in X$ with $p(T x, T y)>0$,

$$
\begin{aligned}
& \alpha(x, y) \beta(x, y) F(p(T x, T y)) \\
& \leq \theta(\phi(M(x, y))) F(N(x, y)) \\
&-D(p(x, y), p(x, T x), p(y, T y), p(T x, T y)),
\end{aligned}
$$

where

$$
\begin{aligned}
& M(x, y)=\max \{p(x, y), p(x, T x), p(y, T y), \\
& \left.\frac{p(x, T y)+p(y, T x)}{2}\right\}, \\
& N(x, y)=\max \{p(x, y), p(x, T x), p(y, T y)\}
\end{aligned}
$$

and $D\left(t_{1}, t_{2}, t_{3}, t_{4}\right)$ is defined as in Definition 16.

(4) $T$ is continuous.

Then, $T$ has a unique fixed point $u \in X$; moreover, $p(u, u)=0$. result.

The following theorem is an another version of our main

Theorem 29. Let $\left(X, p_{b}\right)$ be a complete partial b-metric space. Let $T$ be a self-mapping on $X$ satisfying the following conditions:

(1) $T$ is $(\alpha, \beta)$-admissible.

(2) There exists $x_{0} \in X$ such that $\alpha\left(x_{0}, T x_{0}\right) \geq 1$ and $\beta\left(x_{0}, T x_{0}\right) \geq 1$.

(3) There exist $F \in \Delta_{F}, D \in \Delta_{D}, \theta \in \Theta$, and $\phi \in \Phi$ such that, for all $x, y \in X$ and $s>1$ with $p_{b}(T x, T y)>0$, one has

$$
\begin{aligned}
& \alpha(x, y) \beta(x, y) F\left(s^{\epsilon} p_{b}(T x, T y)\right) \\
& \quad \leq F\left(\theta\left(\phi\left(M_{s}(x, y)\right)\right) N_{s}(x, y)\right) \\
& \quad-D\left(p_{b}(x, y), p_{b}(x, T x), p_{b}(y, T y), p_{b}(T x, T y)\right),
\end{aligned}
$$

where $M_{s}(x, y)$ and $N_{s}(x, y)$ are defined as in Definition 17.

(4) $T$ is continuous.

Then, $T$ has a unique fixed point $u \in X$; moreover, $p_{b}(u, u)=0$.

Proof. The proof of this theorem can be completed on the lines of the proof of Theorem 18, and hence we skip the details.

If $M_{s}(x, y)=N_{s}(x, y)$ and $\phi(t)=t$, in Theorem 29, then we have the following corollary.

Corollary 30. Let $\left(X, p_{b}\right)$ be a complete partial b-metric space. Let $T$ be a self-mapping on $X$ satisfying the following conditions:

(1) $T$ is $(\alpha, \beta)$-admissible.

(2) There exists $x_{0} \in X$ such that $\alpha\left(x_{0}, T x_{0}\right) \geq 1$ and $\beta\left(x_{0}, T x_{0}\right) \geq 1$. 
(3) There exist $F \in \Delta_{F}, D \in \Delta_{D}$, and $\theta \in \Theta$ such that, for all $x, y \in X$ and $s>1$ with $p_{b}(T x, T y)>0$, one has

$$
\begin{aligned}
& \alpha(x, y) \beta(x, y) F\left(s^{\epsilon} p_{b}(T x, T y)\right) \leq F\left(\theta\left(M_{s}(x, y)\right)\right. \\
& \left.\quad \cdot M_{s}(x, y)\right) \\
& \quad-D\left(p_{b}(x, y), p_{b}(x, T x), p_{b}(y, T y), p_{b}(T x, T y)\right) .
\end{aligned}
$$

(4) $T$ is continuous.

Then, $T$ has a unique fixed point $u \in X$; moreover, $p_{b}(u, u)=0$.

By using $D\left(t_{1}, t_{2}, t_{3}, t_{4}\right)=\tau>0, \alpha(x, y)=\beta(x, y)=1$ for all $x, y \in X$, in Theorem 18, we get the following one.

Corollary 31. Let $\left(X, p_{b}\right)$ be a complete partial b-metric space with $s \geq 1$. Let $T$ be a self-mapping on $X$. There exist $F \in \Delta_{F}$, $\theta \in \Theta, \phi \in \Phi$, and $\tau>0$ such that, for all $x, y \in X$ with $p_{b}(T x, T y)>0$,

$$
\begin{aligned}
F\left(s^{\epsilon} p_{b}(T x, T y)\right) \leq & \theta\left(\phi\left(M_{s}(x, y)\right)\right) F\left(N_{s}(x, y)\right) \\
& -\tau,
\end{aligned}
$$

where $M_{s}(x, y)$ and $N_{s}(x, y)$ are defined as in Theorem 18 and $\epsilon>1$. Then, $T$ has a unique fixed point in $X$; moreover, $p_{b}(u, u)=0$.

Remark 32. In view of Remark 6, Corollary 31 generalizes the result of Wardowski [12] for partial metric space and partial $b$-metric space along with Geraghty type contraction.

In [12], the author guaranteed that the F-contraction is the updated version of Banach contraction principle. Wardowski concluded that the Banach contractions are a particular case of $F$-contractions and the author supported his finding by presenting some $F$-contractions which are not Banach contractions.

In view of the aforementioned, we generalized and extended the following results existing in the literature.

Remark 33. Take $\alpha(x, y)=\beta(x, y)=1$ and $\theta(t)=k$, where $k \in[0,1)$ in Theorem 28 is akin to Theorem 5.3 of Matthews [6] in the sense of $F$-contraction.

Remark 34. By introducing Theorem 18, we generalized the results of Chandok [9] and obtained the F-contraction version of [9] in partial $b$-metric spaces.

Remark 35. Taking $\alpha(x, y)=\beta(x, y)=1$ and $\phi(t)=t$ in Theorem 28 is akin to Theorem 2.1 of Altun and Sadarangani [17] for F-contraction.

Remark 36. By taking $\alpha(x, y)=\beta(x, y)=1, \theta(t)=\lambda$, where $\lambda \in[0,1)$ along with zero self-distance in Theorem 28, we extend the Banach contraction principle of Banach [1] in the sense of $F$-contraction.

\section{Applications}

4.1. Fixed Point Results for Graphic Contractions. Following Jachymski [18], let $(X, p)$ be a partial metric space and let $\Delta=$ $\{(x, x): x \in X\}$ denote the diagonal of the cartesian product of $X \times X$. Consider a directed graph $G=(V(G), E(G))$, where $V(G)$ denotes the set of its vertices coinciding with $X$ and $E(G)$ denotes the set of its edges containing all loops, which gives that $E(G)$ is the superset of $\Delta$. Suppose that $G$ has no parallel edges. If $x$ and $y$ are vertices in a graph $G$, then a path in $G$ from $x$ to $y$ of length $l$ is a sequence $\left\{x_{i}\right\}_{i=0}^{l}$ of $(l+1)$ vertices such that $x_{0}=x, x_{l}=y$, and $\left(x_{i-1}, x_{i}\right) \in E(G)$ for $i=1, \ldots, l$. A graph is called connected if there is a path between any two vertices (for more details, see [16, 19]).

Definition 37 (see [18]). A mapping $T: X \rightarrow X$ is called $G$-continuous if given $x \in X$ and sequence $\left\{x_{n}\right\}$ such that $x_{n} \rightarrow x$ as $n \rightarrow \infty,\left(x_{n}, x_{n+1}\right) \in E(G)$, for all $n \in \mathbb{N}$, imply $T x_{n} \rightarrow T x$.

Definition 38. A mapping $T: X \rightarrow X$ is a Banach $G$ contraction or simply $G$-contraction if $T$ preserves edges of $G$; that is,

$$
\begin{gathered}
(x, y) \in E(G) \Longrightarrow \\
(T x, T y) \in E(G),
\end{gathered}
$$

$$
\forall x, y \in X
$$

and $T$ decreases weights of edges of $G$ in the following way:

there exists $k \in(0,1)$

such that $\forall x, y \in X$,

$$
\begin{array}{r}
(x, y) \in E(G) \Longrightarrow \\
d(T x, T y) \leq k d(x, y) .
\end{array}
$$

Next, we introduce the following definition.

Definition 39. Let $(X, p)$ be a partial metric space endowed with a graph $G$ and $T: X \rightarrow X$ is a self-mapping. One says that $T$ is Geraghty type generalized graphic $F$-contraction on $X$. There exist $F \in \Delta_{F}, D \in \Delta_{D}, \theta \in \Theta$, and $\phi \in \Phi$ such that, for all $x, y \in X$ with $p(T x, T y)>0$, one has

$$
\begin{aligned}
F( & p(T x, T y)) \\
\leq & \theta(\phi(M(x, y))) F(N(x, y)) \\
\quad & -D(p(x, y), p(x, T x), p(y, T y), p(T x, T y)),
\end{aligned}
$$

where

$$
\begin{aligned}
& M(x, y)=\max \{p(x, y), p(x, T x), p(y, T y), \\
& \left.\frac{p(x, T y)+p(y, T x)}{2}\right\}, \\
& N(x, y)=\max \{p(x, y), p(x, T x), p(y, T y)\}
\end{aligned}
$$

and $D\left(t_{1}, t_{2}, t_{3}, t_{4}\right)$ is defined as in Definition 16. 
Theorem 40. Let $(X, p)$ be a complete partial metric space endowed with a graph $G$. $T: X \rightarrow X$ is self-mapping on $X$ satisfying the following conditions:

(1) For all $(x, y) \in X,(x, y) \in E(G) \Rightarrow(T x, T y) \in E(G)$.

(2) There exists $x_{0} \in X$ such that $\left(x_{0}, T x_{0}\right) \in E(G)$.

(3) $T$ is $G$-continuous on $(X, p)$.

(4) $T$ is Geraghty type generalized graphic F-contraction on $X$.

Then, $T$ has a fixed point $u \in X$.

Proof. Define $\alpha, \beta: X \times X \rightarrow[0, \infty)$ by

$$
\begin{aligned}
& \alpha(x, y)= \begin{cases}1, & \text { if }(x, y) \in E(G), \\
0, & \text { otherwise, }\end{cases} \\
& \beta(x, y)= \begin{cases}1, & \text { if }(x, y) \in E(G), \\
0, & \text { otherwise. }\end{cases}
\end{aligned}
$$

At first, we will prove that $T$ is an $(\alpha, \beta)$-admissible mapping. Let $x, y \in X$ such that $\alpha(x, y) \geq 1$; then, by the definition of $\alpha$, we obtain that $(x, y) \in E(G)$ and from (1) we get $(T x, T y) \in$ $E(G)$. Again, from the definition of $\alpha$, we have $\alpha(T x, T y) \geq 1$.

Similarly, $\beta(x, y) \geq 1 \Rightarrow \beta(T x, T y) \geq 1$.

Thus, $T$ is an $(\alpha, \beta)$-admissible mapping. From (2), there exists $x_{0} \in X$ such that $\left(x_{0}, T x_{0}\right) \in E(G)$, which yields $\alpha\left(x_{0}, T x_{0}\right) \geq 1$ and $\beta\left(x_{0}, T x_{0}\right) \geq 1$.

From (4), $T$ is Geraghty type generalized graphic $F$ contraction on $X$ and $\alpha(x, y) \geq 1, \beta(x, y) \geq 1$, implies

$$
\begin{aligned}
\alpha(x, y) \beta(x, y) F(p(T x, T y)) & \\
\leq & \theta(\phi(M(x, y))) F(N(x, y)) \\
& -D(p(x, y), p(x, T x), p(y, T y), p(T x, T y)) .
\end{aligned}
$$

Hence, all the conditions of Theorem 28 are satisfied and $T$ has a fixed point. This concludes the proof.

The following example illustrates Theorem 40 involving a directed graph.

Example 41. Let $X=\{1,3,5,7,9\}$ be endowed with the function $p: X \times X \rightarrow[0, \infty)$ defined by

$$
p(x, y)=\max \{x, y\} \text {. }
$$

Then, $(X, p)$ is a complete partial metric space. Consider $T$ : $X \rightarrow X$ as follows:

$$
T x= \begin{cases}1, & \text { if } x \in\{1,3,9\}, \\ 3, & \text { if } x \in\{5,7\} .\end{cases}
$$

Define $\theta:[0, \infty) \rightarrow[0,1)$ by $\theta(t)=1 /(t+1)$. And let $\phi:$ $[0, \infty) \rightarrow[0, \infty)$ be given by $\phi(t)=t / 20$. Let $F(t)=\log t$ for all $t \in \mathbb{R}^{+}$.

Let $G$ be a directed graph such that $V(G)=X$ and $E(G)=$ $\{(x, y): x, y \in\{1,3,5,7,9\}\} \cup \Delta$.
It is easy to deduce that $T$ preserves edges in $G$ and $T$ is $G$ continuous. Also, there exists $x_{0}=1 \in X$ such that $(1, T 1)=$ $(1,1) \in E(G)$. Without loss of generality, we may take $x, y \in$ $X$ such that $x \neq y$. To prove that the contractive condition (68) of Theorem 40 holds, consider the following cases.

Case 1. If $x, y \in E(G)$ such that $x \neq y \in\{1,3,9\}$, then we have to consider the following possibilities.

Case 1(i). If $x=1$ and $y=3$, we get

$$
\begin{aligned}
F(p(T x, T y)) & =\log 1 \\
& \leq \theta(\phi(M(1,3))) \log (N(1,3))-\tau,
\end{aligned}
$$

in which $M(1,3)=N(1,3)=3$ and $\tau \in(0,0.4]$.

Case 1(ii). If $x=1$ and $y=9$, we have

$$
\begin{aligned}
F(p(T x, T y)) & =\log 1 \\
& \leq \theta(\phi(M(1,9))) \log (N(1,9))-\tau,
\end{aligned}
$$

in which $M(1,9)=N(1,9)=9$ and $\tau \in(0,0.6]$.

Case 1(iii). If $x=3$ and $y=9$, we obtain

$$
\begin{aligned}
F(p(T x, T y)) & =\log 1 \\
& \leq \theta(\phi(M(3,9))) \log (N(3,9))-\tau,
\end{aligned}
$$

in which $M(3,9)=N(3,9)=9$ and $\tau \in(0,0.6]$.

Case 2. If $x, y \in E(G)$ such that $x \neq y \in\{5,7\}$, then inequality (68) turns into

$$
\begin{aligned}
F(p(T x, T y)) & =\log 3 \\
& \leq \theta(\phi(M(5,7))) \log (N(5,7))-\tau,
\end{aligned}
$$

in which $M(5,7)=N(5,7)=7$ and $\tau \in(0,0.14]$.

Case 3. If $x, y \in E(G)$ such that $x \in\{1,3,9\}$ and $y \in\{5,7\}$, then we have to consider the following six subcases.

Case 3(i). If $x=1$ and $y=5$, we get

$$
\begin{aligned}
F(p(T x, T y)) & =\log 3 \\
& \leq \theta(\phi(M(1,5))) \log (N(1,5))-\tau .
\end{aligned}
$$

Indeed, $M(1,5)=N(1,5)=5$ and $\tau \in(0,0.08]$.

Case 3(ii). If $x=1$ and $y=7$, we get

$$
\begin{aligned}
F(p(T x, T y)) & =\log 3 \\
& \leq \theta(\phi(M(1,7))) \log (N(1,7))-\tau .
\end{aligned}
$$

Indeed, $M(1,7)=N(1,7)=7$ and $\tau \in(0,0.14]$.

Case 3(iii). If $x=3$ and $y=5$, we get

$$
\begin{aligned}
F(p(T x, T y)) & =\log 3 \\
& \leq \theta(\phi(M(3,5))) \log (N(3,5))-\tau .
\end{aligned}
$$




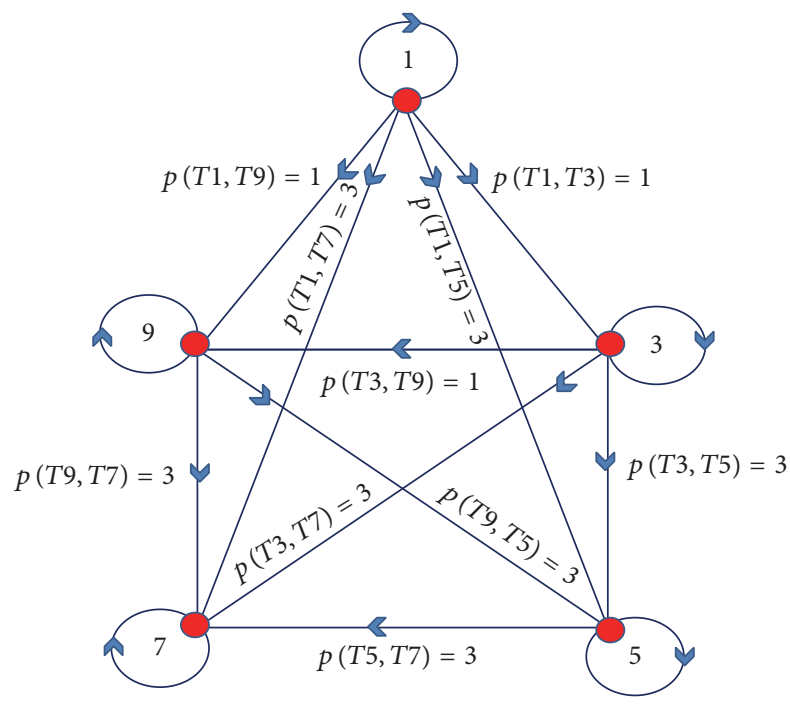

Figure 6: The graph $G$ defined in Example 41.

Indeed, $M(3,5)=N(3,5)=5$ and $\tau \in(0,0.07]$.

Case 3(iv). If $x=3$ and $y=7$, we get

$$
\begin{aligned}
F(p(T x, T y)) & =\log 3 \\
& \leq \theta(\phi(M(3,7))) \log (N(3,7))-\tau .
\end{aligned}
$$

Indeed, $M(3,7)=N(3,7)=7$ and $\tau \in(0,0.14]$.

Case 3(v). If $x=9$ and $y=5$, we get

$$
\begin{aligned}
F(p(T x, T y)) & =\log 3 \\
& \leq \theta(\phi(M(9,5))) \log (N(9,5))-\tau .
\end{aligned}
$$

Case 3(vi). If $x=9$ and $y=7$, we get

$$
\begin{aligned}
F(p(T x, T y)) & =\log 3 \\
& \leq \theta(\phi(M(9,7))) \log (N(9,7))-\tau .
\end{aligned}
$$

Indeed, $M(9,7)=N(9,7)=9$ and $\tau \in(0,0.18]$.

Figure 6 represents the graph with all the possible cases.

Hence, all the conditions of Theorem 40 are satisfied and Theorem 40 ensures the existence of fixed point of $T$, which is $u=1$.

It needs to be mentioned that the following definition will be useful in the following subsection.

Definition 42. Let $\Psi$ denote the class of those functions $\psi$ : $[0, \infty) \rightarrow[0, \infty)$ which satisfies the following conditions:

(i) $\psi$ is continuous, subadditive, and nondecreasing.

(ii) For each $t>0, \psi(t)<t$.

(iii) $\theta(t)=\psi(t) / t \in \Theta$.

(iv) $\psi$ is positive in $(0, \infty)$ with $\psi(0)=0$.

For example, $\psi(x)=x /(x+1)$ and $\psi(x)=\ln (x+1)$ are in $\Psi$.
4.2. Application to Solutions of Ordinary Differential Equations. Consider the following first-order periodic boundary value problem:

$$
\begin{aligned}
& u^{\prime}(t)=k(t, u(t)), \quad t \in I=[0, T], \\
& u(0)=u(T),
\end{aligned}
$$

where $T>0$ and $k: I \times \mathbb{R} \rightarrow \mathbb{R}$ is a continuous function.

Consider the space $X=C(I, \mathbb{R})$ of all real continuous functions on $I=[0, T]$. Let $p_{b}: X \times X \rightarrow \mathbb{R}^{+}$be given by

$$
p_{b}(u, v)=\max _{t \in I}|u(t)-v(t)|^{q},
$$

for all $u, v \in X$, where $q>1$ and $r \geq 0$. Obviously, the space $\left(X, p_{b}\right)$ is a complete partial $b$-metric space with parameter $s=2^{q-1}$. The space $X=C(I, \mathbb{R})$ can also be equipped with the following order relation:

$$
\begin{gathered}
x \leq y \Longleftrightarrow \\
x(t) \leq y(t)
\end{gathered}
$$

$\forall t \in I, x, y \in C(I, \mathbb{R})$.

Definition 43. An element $\gamma \in X$ is called a lower solution for problem (84) if

$$
\begin{aligned}
& \gamma^{\prime}(t)=k(t, \gamma(t)), \quad t \in I=[0, T], \\
& \gamma(0)=\gamma(T) .
\end{aligned}
$$

Theorem 44. Consider problem (84) and assume the following:

(1) There exists $\lambda>0$ and functions $\xi, \eta: \mathbb{R} \times \mathbb{R} \rightarrow \mathbb{R}$ such that, for any $x, y \in \mathbb{R}$, with $x \geq y$ and $\tau>0$,

$$
\begin{aligned}
& |k(t, x(t))+\lambda x(t)-k(t, y(t))-\lambda y(t)| \\
& \leq \frac{\lambda}{2^{\epsilon(q-1) / q}} \sqrt[q]{\ln \left(|x(t)-y(t)|^{q}+1\right) e^{-\tau}}
\end{aligned}
$$

for all $t \in I$ with $\xi(x, y)>0$ and $\eta(x, y)>0$.

(2) there exists $x_{0} \in X$ such that $\xi\left(x_{0}(t), f x_{0}(t)\right)>0$ and $\eta\left(x_{0}(t), f x_{0}(t)\right)>0$ for all $t \in I$, where the function $f: C(I, \mathbb{R}) \rightarrow C(I, \mathbb{R})$ is defined by

$$
f u(t)=\int_{0}^{T} G(t, s)[k(s, u(s))+\lambda u(s)] d s .
$$

(3) For each $t \in I$ and $x, y \in X$, one has

$$
\begin{gathered}
\xi(x(t), y(t))>0 \Longrightarrow \\
\xi(f x(t), f y(t))>0, \\
\eta(x(t), y(t))>0 \Longrightarrow \\
\eta(f x(t), f y(t))>0 .
\end{gathered}
$$

Then, the existence of a lower solution for the periodic boundary value problem provides a unique solution for (84). 
Proof. Problem (84) is equivalent to the integral equation

$$
u(t)=\int_{0}^{T} G(t, s)[k(s, u(s))+\lambda u(s)] d s
$$

in which

$$
G(t, s)= \begin{cases}\frac{e^{\lambda(T+s-t)}}{e^{\lambda T}-1}, & 0 \leq s \leq t \leq T \\ \frac{e^{\lambda(s-t)}}{e^{\lambda T}-1}, & 0 \leq t \leq s \leq T\end{cases}
$$

It is easy to note that if $u \in C(I, \mathbb{R})$ is a fixed point of $f$, then $u \in C^{1}(I, \mathbb{R})$ is a solution of problem (84).

For any $u, v \in X$ such that $\xi(u(t), v(t))>0$ and $\eta(u(t), v(t))>0$, where $u \geq v$, we have

$$
\begin{aligned}
& 2^{\epsilon(q-1) / q}|f u(t)-f v(t)| \\
& =2^{\epsilon(q-1) / q} \mid \int_{0}^{T} G(t, s)[k(s, u(s))+\lambda u(s)] d s \\
& -\int_{0}^{T} G(t, s)[k(s, v(s))+\lambda v(s)] d s \\
& \leq 2^{\epsilon(q-1) / q} \int_{0}^{T}|G(t, s)| \mid k(s, u(s))+\lambda u(s) \\
& -k(s, v(s))-\lambda v(s) \mid d s \\
& \leq 2^{\epsilon(q-1) / q} \int_{0}^{T}|G(t, s)| \\
& \cdot \frac{\lambda}{2^{\epsilon(q-1) / q}} \sqrt[q]{\ln \left(|u(s)-v(s)|^{q}+1\right) e^{-\tau}} d s \\
& \leq \int_{0}^{T}|G(t, s)| \lambda \sqrt[q]{\ln \left(|u(s)-v(s)|^{q}+1\right) e^{-\tau}} d s \\
& \leq \max _{t \in I} \int_{0}^{T}|G(t, s)| \lambda \sqrt[q]{\ln \left(|u(s)-v(s)|^{q}+1\right) e^{-\tau}} d s \\
& \leq \lambda \sqrt[a]{\ln \left(p_{b}(u, v)+1\right) e^{-\tau}} \max _{t \in I} \int_{0}^{T} G(t, s) d s \\
& \leq \lambda \sqrt[q]{\ln \left(p_{b}(u, v)+1\right) e^{-\tau}} \max _{t \in I}\left[\int_{0}^{t} \frac{e^{\lambda(T+s-t)}}{e^{\lambda T}-1} d s\right. \\
& \left.+\int_{t}^{T} \frac{e^{\lambda(s-t)}}{e^{\lambda T}-1} d s\right] \\
& \leq \lambda \sqrt[a]{\ln \left(p_{b}(u, v)+1\right) e^{-\tau}}\left[\frac { 1 } { \lambda ( e ^ { \lambda T } - 1 ) } \left(e^{\lambda T}\right.\right. \\
& \left.\left.-e^{\lambda(T-t)}+e^{\lambda(T-t)}-1\right)\right] \leq \sqrt[q]{\ln \left(p_{b}(u, v)+1\right) e^{-\tau}},
\end{aligned}
$$

which yields

$$
\begin{aligned}
& 2^{\epsilon(q-1)}|f u(t)-f v(t)|^{q} \leq \ln \left(p_{b}(u, v)+1\right) e^{-\tau}, \\
& 2^{\epsilon(q-1)} p_{b}(f u, f v) \leq \ln \left(M_{s}(u, v)+1\right) e^{-\tau} \\
& \quad \leq \psi\left(M_{s}(u, v)\right) e^{-\tau} \leq \frac{\psi\left(M_{s}(u, v)\right)}{M_{s}(u, v)} M_{s}(u, v) e^{-\tau}, \\
& 2^{\epsilon(q-1)} p_{b}(f u, f v) \leq \theta\left(M_{s}(u, v)\right) M_{s}(u, v) e^{-\tau},
\end{aligned}
$$

where

$$
\begin{aligned}
& M_{s}(u, v)=\max \left\{p_{b}(u, v), p_{b}(u, f u), p_{b}(v, f v),\right. \\
& \left.\frac{1}{2 s}\left[p_{b}(u, f v)+p_{b}(v, f u)\right]\right\} .
\end{aligned}
$$

Consequently, by passing to logarithms, the above inequality turns into

$$
\begin{aligned}
& \log \left(2^{\epsilon(q-1)} p_{b}(f u, f v)\right) \\
& \quad \leq \log \left(\theta\left(M_{s}(u, v)\right) M_{s}(u, v)\right)+\log e^{-\tau} .
\end{aligned}
$$

This gives

$$
F\left(s^{\epsilon} p_{b}(f u, f v)\right) \leq F\left(\theta\left(M_{s}(u, v)\right) M_{s}(u, v)\right)-\tau,
$$

for $F(t)=\log t, t>0$. Define $\alpha, \beta: X \times X \rightarrow[0, \infty)$ by

$$
\begin{aligned}
& \alpha(u, v)= \begin{cases}1, & \text { if } \xi(u(t), v(t))>0, t \in I, \\
0, & \text { otherwise, }\end{cases} \\
& \beta(u, v)= \begin{cases}1, & \text { if } \eta(u(t), v(t))>0, t \in I, \\
0, & \text { otherwise, }\end{cases}
\end{aligned}
$$

for all $u, v \in X$. Hence,

$$
\begin{aligned}
& \alpha(u, v) \beta(u, v) F\left(s^{\epsilon} p_{b}(f u, f v)\right) \\
& \quad \leq F\left(\theta\left(M_{s}(u, v)\right) M_{s}(u, v)\right)-\tau .
\end{aligned}
$$

Now, using condition (2) and in account of the definition of $\alpha(u, v)$ and $\beta(u, v)$, we have

$$
\begin{aligned}
& \alpha\left(x_{0}, f x_{0}\right)=1 \geq 1, \\
& \beta\left(x_{0}, f x_{0}\right)=1 \geq 1 .
\end{aligned}
$$

From condition (3), we get

$$
\begin{aligned}
& \alpha(u, v) \geq 1 \Longrightarrow \\
& \xi(u(t), v(t))>0 \Longrightarrow \\
& \xi(f u(t), f v(t))>0 \Longrightarrow \\
& \alpha(f u, f v) \geq 1, \\
& \beta(u, v) \geq 1 \Longrightarrow \\
& \eta(u(t), v(t))>0 \Longrightarrow \\
& \eta(f u(t), f v(t))>0 \Longrightarrow \\
& \beta(f u, f v) \geq 1 .
\end{aligned}
$$


Thus, $f$ is an $(\alpha, \beta)$-admissible mapping. Finally, let $\gamma$ be a lower solution for (84). Then, from [20], we have $\gamma \leq f(\gamma)$. Hence, all the hypotheses of Corollary 30 are satisfied and thus the mapping $f$ has a fixed point that is a solution in $X=C(I, \mathbb{R})$ of problem $(84)$.

\section{Open Problems for Future Reading}

(i) In Theorem 18 , can $(\alpha, \beta)$-admissible Geraghty type generalized $F$-contraction be improved by cyclic contraction?

(ii) Can Theorem 18 be extended and generalized by replacing Geraghty contraction by hybrid rational Geraghty contraction?

\section{Competing Interests}

The authors declare that there are no competing interests regarding the publication of this paper.

\section{References}

[1] S. Banach, "Sur les oprationes dans les ensembles abstraits et leur application aux quation intgrales," Fundamenta Mathematicae, vol. 3, pp. 133-181, 1922.

[2] M. A. Geraghty, "On contractive mappings," Proceedings of the American Mathematical Society, vol. 40, pp. 604-608, 1973.

[3] I. A. Bakhtin, "The contraction mapping principle in quasi metric spaces," Funct. Anal. Unianowsk Gos. Ped. Inst, vol. 30, pp. 26-37, 1989.

[4] S. Czerwik, "Contraction mappings in b-metric spaces," Acta Mathematica et Informatica Universitatis Ostraviensis, vol. 1, pp. 5-11, 1993.

[5] S. Czerwik, "Nonlinear set-valued contraction mappings in b-metric spaces," Atti del Seminario Matematico e Fisico dell'Universita di Modena e Reggio Emilia, vol. 46, pp. 263-276, 1998.

[6] S. G. Matthews, "Partial metric topology," in Proceedings of the 8th Summer Conference on General Topology and Application, vol. 728, pp. 183-197, Annals of the New York Academy of Sciences, 1994.

[7] E. Karapinar, W. Shatanawi, and K. Tas, "Fixed point theorem on partial metric spaces involving rational expressions," Miskolc Mathematical Notes, vol. 14, no. 1, pp. 135-142, 2013.

[8] B. Samet, C. Vetro, and P. Vetro, "Fixed point theorems for $\alpha-\psi$-contractive type mappings," Nonlinear Analysis: Theory, Methods \& Applications, vol. 75, no. 4, pp. 2154-2165, 2012.

[9] S. Chandok, "Some fixed point theorems for $(\alpha, \beta)$-admissible geraghty type contractive mappings and related results," Mathematical Sciences, vol. 9, no. 3, pp. 127-135, 2015.

[10] S. Shukla, "Partial b-metric spaces and fixed point theorems," Mediterranean Journal of Mathematics, vol. 11, no. 2, pp. 703711, 2014.

[11] Z. Mustafa, J. R. Roshan, V. Parvaneh, and Z. Kadelburg, "Some common fixed point results in ordered partial b-metric spaces," Journal of Inequalities and Applications, vol. 2013, article no. 562, 2013.

[12] D. Wardowski, "Fixed points of a new type of contractive mappings in complete metric spaces," Fixed Point Theory and Applications, vol. 2012, article no. 94, 2012.
[13] N.-A. Secelean, "Iterated function systems consisting of Fcontractions," Fixed Point Theory and Applications, vol. 2013, article 277, 2013.

[14] H. Piri and P. Kumam, "Some fixed point theorems concerning F-contraction in complete metric spaces," Fixed Point Theory and Applications, vol. 2014, article no. 210, 2014.

[15] M. Abbas, B. Ali, O. Rizzo, and C. Vetro, "Fuzzy fixed points of generalized F2-geraghty type fuzzy mappings and complementary results," Nonlinear Analysis. Modelling and Control, vol. 21, no. 2, pp. 274-292, 2016.

[16] F. Bojor, "Fixed point theorems for Reich type contractions on metric spaces with a graph," Nonlinear Analysis. Theory, Methods \& Applications, vol. 75, no. 9, pp. 3895-3901, 2012.

[17] I. Altun and K. Sadarangani, "Generalized Geraghty type mappings on partial metric spaces and fixed point results," Arabian Journal of Mathematics, vol. 2, no. 3, pp. 247-253, 2013.

[18] J. Jachymski, "The contraction principle for mappings on a metric space with a graph," Proceedings of the American Mathematical Society, vol. 136, no. 4, pp. 1359-1373, 2008.

[19] I. Beg, A. R. Butt, and S. Radojević, "The contraction principle for set valued mappings on a metric space with a graph," Computers \& Mathematics with Applications, vol. 60, no. 5, pp. 1214-1219, 2010.

[20] J. Harjani and K. Sadarangani, "Fixed point theorems for weakly contractive mappings in partially ordered sets," Nonlinear Analysis: Theory, Methods \& Applications, vol. 71, no. 7-8, pp. 34033410, 2009. 


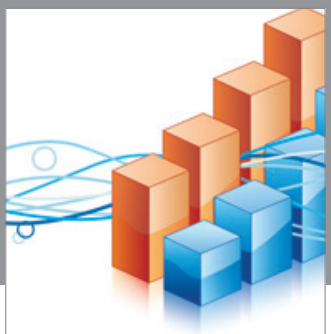

Advances in

Operations Research

vatem alat4

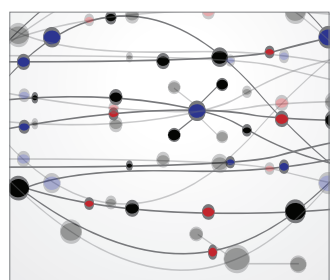

\section{The Scientific} World Journal
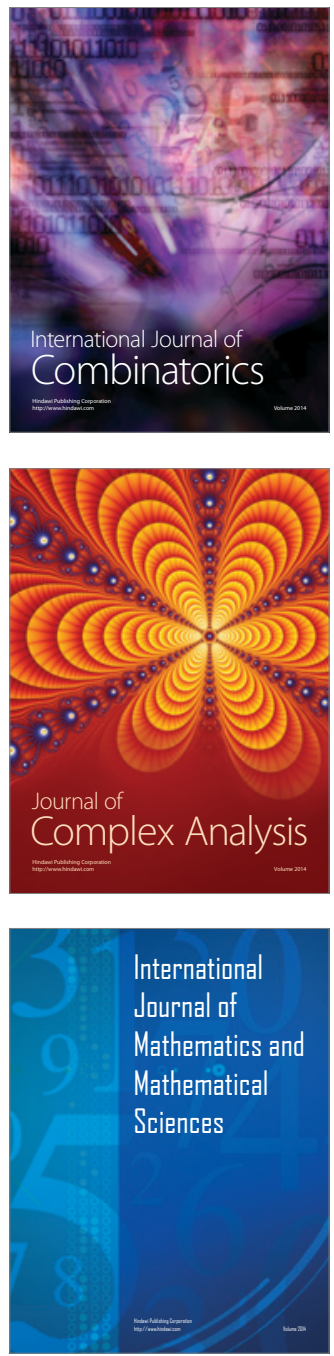
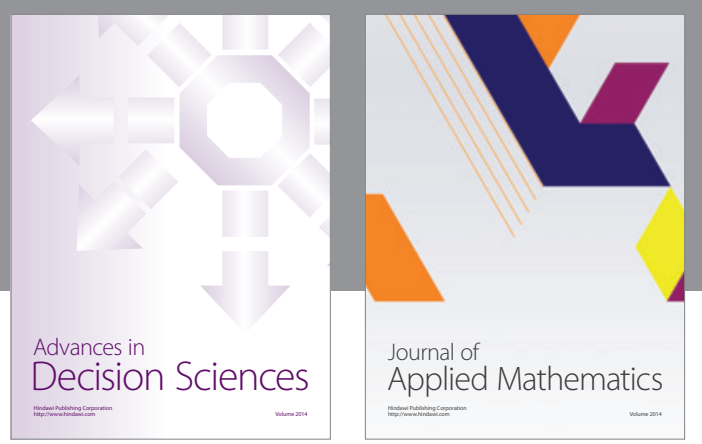

Algebra

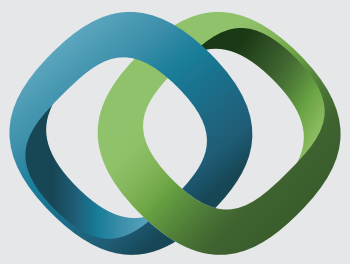

\section{Hindawi}

Submit your manuscripts at

https://www.hindawi.com
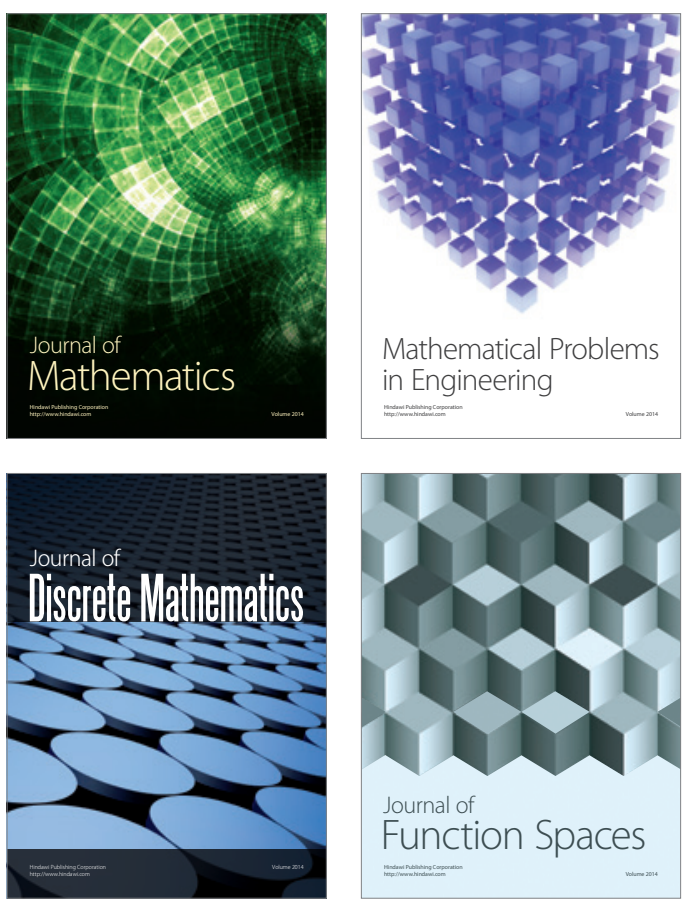

Mathematical Problems in Engineering
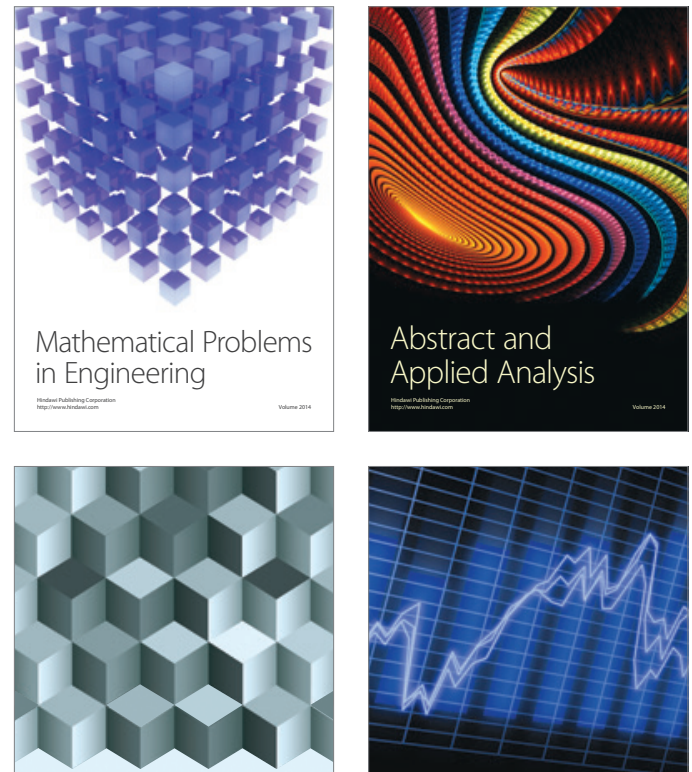

Journal of

Function Spaces

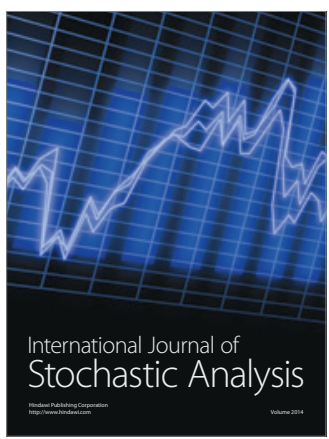

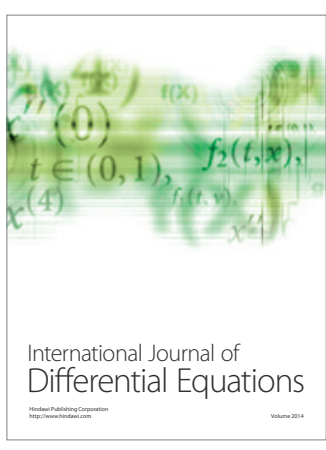
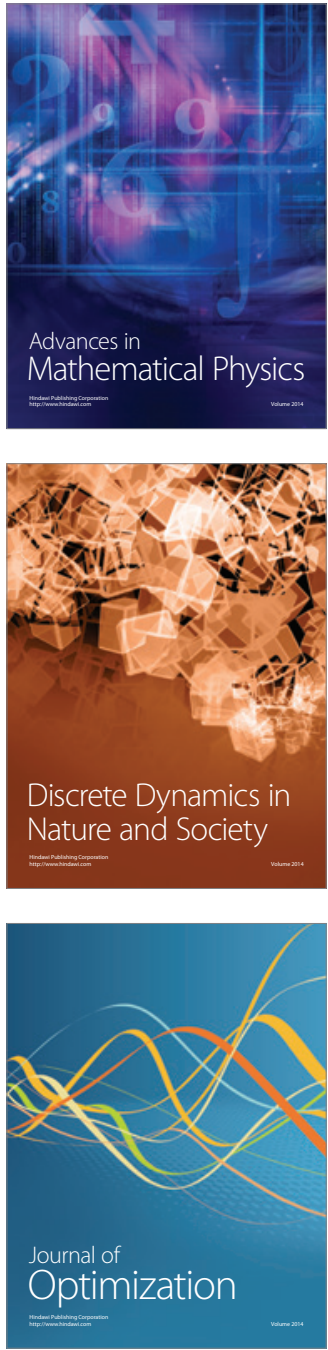